\title{
CYP2C19*2 polymorphism influenced response to clopidogrel treatment but was not related to restenosis in atherosclerotic smokers
}

\author{
I.R. da Costa $^{1,2}$, K.F. Borges ${ }^{1}$, T.R. dos $\operatorname{Santos}^{1}$, I.A. Bento ${ }^{1}$, \\ B.O. Siqueira ${ }^{1}$, K.S.F. e Silva ${ }^{3}$, A.M. Barbosa, ${ }^{2,4}$, F.L. Campedelli, \\ M.H. Lagares ${ }^{5}$, L.C.A. Gianotti ${ }^{4,5}$, F.O. de Souza ${ }^{4,5}$, I.B. Lima ${ }^{1,5}$, \\ U.S. Vilarinho ${ }^{1,4}$ and K.K.V.O. Moura ${ }^{1,2,3,4,5}$ \\ ${ }^{1}$ Escola de Ciências Médicas, Farmacêuticas e Biomédicas, Pontifícia \\ Universidade Católica de Goiás, Goiânia, GO, Brasil \\ ${ }^{2}$ Instituto de Biotecnologia e Biodiversidade, Universidade Federal de \\ Goiás, UFG, Goiânia, GO, Brasil \\ ${ }^{3}$ Instituto de Ciências Biológicas, Universidade Federal de Goiás, UFG, \\ Goiânia, GO, Brasil \\ ${ }^{4}$ Centro de Pesquisas Replicon, Faculdade de Ciências Agrárias e \\ Biológicas, Pontifícia Universidade Católica de Goiás, Goiânia, GO, Brasil \\ ${ }^{5}$ Departamento de Genética, Pontifícia Universidade Católica de Goiás, \\ Goiânia, GO, Brasil
}

Corresponding author: K.S.F. e Silva

E-mail: smallbinho@hotmail.com

Genet. Mol. Res. 19 (3): gmr18641

Received May 24, 2020

Accepted July 03, 2020

Published July 31, 2020

DOI http://dx.doi.org/10.4238/gmr18641

ABSTRACT. Atherosclerosis is an important cardiovascular disease due to its high mortality rate worldwide. Risk factors such as chronic use of cigarettes, poor diet, sedentary lifestyle, diabetes mellitus and genetic factors significantly contribute to the disease. The CYP2C19 gene is a well-studied target for cardiovascular disease treatment. Polymorphisms in the CYP2C19 gene, which encodes cytochrome P450 enzymes, may result in inefficiency of the drug clopidogrel. Identification of CYP2C19 polymorphisms may improve preventive treatment and the prognosis of the disease. We investigated if the CYP2C19*2 polymorphism influences the onset of restenosis in smokers. We analyzed 200 patient 
blood samples from the Cardiology and Peripheral Vascular Surgery clinics of hospitals in Goiânia, Brazil. The DNA samples were submitted to PCR amplification and the product obtained was submitted to electrophoresis. We found that $34 \%$ of the atherosclerotic smokers had stents, and $46 \%$ of them developed restenosis. The frequency of the CYP2C19*2 polymorphism showed that $34 \%$ of atherosclerotic smokers who had at least one polymorphic allele had a stent and $45 \%$ of these patients developed restenosis. These differences were not significant. Although the CYP2C19*2 polymorphism alters the response to clopidogrel, its association with smoking did not influence the development of restenosis.

Key words: Atherosclerosis; Stent; Restenosis; CYP2C19*2; Tobacco smoking

\section{INTRODUCTION}

Atherosclerosis is an inflammatory cardiovascular disease with a chronic and multifactorial character that affects the progression of atherogenesis. The disease develops as a response to endothelial aggression and mainly affects the tunica intima and media of medium and large caliber arteries. Usually the first lesions occur in childhood through the accumulation of cholesterol in macrophages, leading to the formation of foam cells (Chistiakov et al., 2017). According to the World Health Organization, cardiovascular diseases are the leading cause of death in the world. Cardiovascular disease killed about 17.7 million people in 2015, which represented about 31\% of global deaths (Lüscher, 2018). Around 300,000 people suffer from heart attack each year in Brazil, causing considerable economic burden.

The onset of atherosclerotic plaque formation occurs when the endothelium suffers aggression caused by physiological, genetic and environmental factors. This leads to a decrease in the production of anticoagulants and an increase in the production of procoagulant and vasoactive molecules. Endothelium damage increases its permeability to lipoproteins. favoring the retention of these molecules in the sub-endothelial space. The result is an inflammatory process maintained by vascular permeability and local adherence of leukocytes and platelets. The recruitment of monocytes and T lymphocytes, and an increase in the number of smooth muscle cells, promote thickening of the vessel walls. After lesion formation, a fibrous capsule with necrotic tissues and lipids can aggravate the disease (Friedlander and Altman, 2001).

Atherosclerotic lesions are more common in men than in women due to the fact that estrogen is a protective factor. However, after menopause the risk of women developing atherosclerosis is similar to that in male patients. The main risk factors of the disease are diabetes mellitus, hyper-caloric diet, hypertension, alcoholism, genetic polymorphisms and smoking (Pires et al., 2007).

A smoking habit is a risk factor because inhibits the synthesis of high-density lipoprotein (HDL), the so-called good cholesterol. A decrease in HDL leads to an increase in the levels of low-density lipoprotein (LDL) and the very low-density lipoprotein (VLDL). The accumulation and consequently deposition of LDL and VLDL in the tunica intima of vessels mark the onset of atherogenesis (McGill and McMahan, 1998). The 
cigarette contains substances capable of increasing blood viscosity (Almarshad and Hassan, 2016), affect platelet functions and increase the risk of thrombosis (Anand, 2017).

More than 400 genes have been associated with the onset of atherosclerosis. CYP (cytochrome P450), GSTs (glutathione S-transferases), ApoE (apolipoprotein E) and eNOS (endothelial nitric oxide synthase) are commonly investigated genes in atherosclerotic patients. Genetic variability in these genes are considered polymorphisms when they occur in the population at a rate of at least $1 \%$. Polymorphisms are efficient genetic markers because they are transmitted associated with other genes located around their chromosomal regions (Balasubramanian et al., 2004).

Genetic polymorphisms are responsible for human diversity and influence the development of several diseases (Syvänen, 2001). Polymorphisms may be responsible for the pharmacokinetic and pharmacodynamic particularities of each individual (Cooper et al., 2005), principally when they affect genes encoding enzymes. For example, the polymorphisms CYP2C19*2 and $* 3$ are factors that significantly interfere in the formation of atheromatous plaque.

Angioplasty is one of the main and most effective methods for the treatment of atherosclerosis. The procedure is based on the remodeling of the atheromatous plaque; however, development of restenosis is frequent among atherosclerotic patients (Caramori et al., 1997). Atherosclerotic patients with stents should be treated with antiplatelet drugs. Clopidogrel is one of these drugs and requires the activation of the CYP gene in order to present a proper response (Jia et al., 2013; Messner et al., 2014).

Atherosclerosis is a public health problem in worldwide. The CYP2C19 gene is a well-studied target for cardiovascular disease treatment. Polymorphisms in the CYP2C19 gene, which encodes cytochrome P450 enzymes, may result in inefficient response of the drug clopidogrel. Identification of CYP2C19 polymorphisms may affect preventive treatments and the prognosis of the disease. We investigated whether the CYP2C19*2 polymorphism influences restenosis development and stent replacement in atherosclerotic patients with a smoking habit.

\section{MATERIAL AND METHODS}

We collected 200 peripheral blood samples from patients with atherosclerosis from October 2014 to February 2015. Patients were attended at the service of cardiology and peripheral vascular surgery of Goiânia Hospitals. Atherosclerosis was confirmed by echo Doppler, angiotomography and/or digital angiography, angiotomography and/or cine coronary angiography.

The patients answered a questionnaire and signed a free and informed consent form. Atherosclerosis patients who presented results for the CYP2C19*2 polymorphism participated in the research. Patients without the pathology or who did not obtain amplification for this polymorphism were excluded.

DNA extractions were initiatited with purification of the samples, according to the instructions of the GFXTM Kit (Amersham Pharmacia Biotech, USA). After extraction, the samples were subjected to quantification on a NanoVue ${ }^{\mathrm{TM}}$ Plus spectrophotometer following the manufacturer's instructions, and only samples whose concentration was greater than $5 \mathrm{ng} / \mu \mathrm{L}$ were used. 
The DNA samples were subjected to amplification, aiming to detect the CYP2C19*2 polymorphism. The PCR reactions were performed according to the protocol proposed by Sambrook et al. (2001), with a final volume of $25 \mu \mathrm{L}$ (Table 1). The product obtained was subjected to electrophoresis on an agarose gel in an electric field of $100 \mathrm{~V} / \mathrm{cm}$ and stained with ethidium bromide $(5 \mathrm{mg} / \mathrm{mL})$ and then visualized on a BIORAD photodocumenter (Bio-Rad, Hercules, California, USA).

Table 1. Primer sequences for the CYP2C19*2 polymorphism analysis.

\begin{tabular}{|c|c|c|c|c|}
\hline Allele & Primers & PCR (37 cycles) & $\begin{array}{l}\text { Restriction } \\
\text { Enzyme }\end{array}$ & DNA fragment \\
\hline $\begin{array}{rl}* & 2 \mathrm{FP} \\
\mathrm{RP}\end{array}$ & $\begin{array}{l}5^{\prime} \text {-AATTACAACCAGAGCTTGGC-3' } \\
5^{\prime} \text {-TATCACTTTCCATAAAAGCAAG-3' }\end{array}$ & $\begin{array}{l}94^{\circ} \mathrm{C} 60^{\prime}, \\
58^{\circ} \mathrm{C} 30^{\prime}, \\
72^{\circ} \mathrm{C} 30^{\prime}\end{array}$ & MspI & $\begin{array}{l}\text { AF169 } \\
\text { HWT 120,49 } \\
\text { HE 169,120,49 } \\
\text { HM } 169\end{array}$ \\
\hline
\end{tabular}

The data regarding the polymorphisms were organized in Excel spreadsheets. Statistical analysis was performed by chi-square test $\left(\chi^{2}\right)$ in order to determine possible relationships between the polymorphism and disease. Values of $\mathrm{P}<0.05$ were considered statistically significant and the statistical tests were performed with the BioEstat ${ }^{\circledR} 5.3$ software. This research was approved by the Research Ethics Committee of Pontifical Catholic University of Goiás, with protocol number 35322624.3.0000.0037.

\section{RESULTS}

Among non-smoking atherosclerotic patients $23.3 \%$ had a stent, while $33.8 \%$ of smoking patients also had a stent. Regarding restenosis, 53.3\% of non-smokers had this complication and $45.8 \%$ of smokers also did (Table 2). These differences were not statistically significant.

Table 2. Frequency of smoking, stents and restenosis in the atherosclerotic patients.

\begin{tabular}{lcll}
\hline & & & Smokers \\
\cline { 2 - 4 } Stent & Non smokers & $\mathbf{n}$ & P* \\
\hline With & 99 & 47 & 0.1079 \\
Without & 30 & 24 & 71 \\
Total & 129 & & 13 \\
Complications & & 11 & 0.5839 \\
Without restenosis & 14 & 24 & \\
With restenosis & 16 &
\end{tabular}

*Chi-squared Test.

Among atherosclerotic smokers with stents one third had the wild genotype for CYP2C19*2, while about a third of atherosclerotic smokers with stents had at least one polymorphic allele for CYP2C19*2 (Table 3 ). Regarding restenosis, half (3/6) of carriers of 
the wild gene had restenosis, while about $44 \%$ (8/18) of those who had at least one polymorphic allele had restenosis. These differences were not significant.

Table 3. Polymorphism of the CYP2C19*2 gene in smoking patients in relation to stenting and restenosis.

\begin{tabular}{llll}
\hline & CYP2C19*1*1 & CYP2C19*1/*2 \\
Stent & CYP2C19*2/*2 & P \\
\hline With & 12 & $\mathbf{n}$ & $0.611 *$ \\
Without & 6 & 35 & \\
Total & 18 & 53 & \\
Complications & & 10 & $0.8132 * *$ \\
Without restenosis & 3 & 8 & \\
With restenosis & 3 & 18 & \\
Total & 6 & & \\
\hline *Chi-squared Test. ** G Test & & &
\end{tabular}

\section{DISCUSSION}

Various studies have shown that smoking has a strong influence on cardiovascular disease. The cigarette contains about 4,000 different chemical substances; these can promote changes in the body, such as mutations in the CYP family (Messner, 2014). According to Lee et al. (2015), nicotine can increase blood pressure by up to $15 \mathrm{~mm} \mathrm{Hg}$ for about 30 minutes after using cigarettes, which is a risk factor for atherogenesis. Celermajer et al. (1992) published a study that demonstrated a decrease in flow-mediated dilation in young adults who were smokers, this being one of the first damages caused by smoking in the human body. Experimental studies have suggested a link between cellular proatherogenesis and the molecular effects of cigarettes and the onset of cardiovascular disease (Messner, 2014).

Craig et al. (1989) demonstrated that in smoking patients there is an increase in total cholesterol, LDL, VLDL and triglycerides in the serum, while HDL and apoprotein A1 are in low concentrations. Likewise Neufeld et al. (1997) showed a link between passive smokers and low HDL levels. In their study, it was observed that children who live daily with smokers had low HDL rates.

Cigarettes have several influences on coagulation; one of them is endothelial dysfunction, it delays endothelial healing, thus leaving the smoker who undergoes stent implantation to be more susceptible to in-stent restenosis (Bossard, 2017). In 2017, Bossard and collaborators analyzed smoking in stent patients, where there was no statistically significant difference between smoking and the need for stenting. Result similar to that found in the present research. In 2015, Tanindi analyzed Turkish patients seen at the Ufuk University hospital in Ankara. The majority of patients who had a stent were smokers and had restenosis. This result is in line with the present study, where we found no association between smoking and the development of restenosis.

The CYP2C19 gene is one of those responsible for encoding cytochrome p450 enzymes, these enzymes act mainly in the endoplasmic reticulum of hepatocytes, thus being responsible for the metabolism of drugs. One of the drugs that these enzymes act on is clopidogrel, which in its active form, inhibits the platelet surface protein P2RY12, responsible for their aggregation (Nie et al., 2017). 
In their study, Ayesh et al. (2019), analyzed patients at the European Gaza Hospital, in Palestine, where all of them had undergone surgical intervention in the coronary artery. Of these $15.5 \%$ had CYP2C19*2, the data being statistically significant. Grines et al. stated in his 2007 study that treatment with clopidogrel for 24 months interrupted after placement of the drug-eluting stent significantly reduces the risk of death for these patients. In addition, the guidelines recommend the continuous use of the drug for at least 12 months after the conventional stent placement procedure. In the current study, $34.0 \%$ of the patients who needed to have a stent were smokers, but the difference between the groups was not statistically significant.

In 2018, Idrissi and colleagues analyzed the genes of CYP2C19*2 and CYP2C19*3 of Moroccan patients in the cardiology department located at Hospital Universitário de Hassan II. They did not obtain statistically significant results when they analyzed the alleles separately. However, it was statistically significant when analyzing the three alleles together (CYP2C19*2, CYP2C19*3 and CYP2C19*17). In the present study, CYP2C19*2 was analyzed and no statistically significant differences were obtained, corroborating with the data found. The same is true for the analysis performed for eNOS patients (Barbosa et al., 2020).

Yi et al. (2016) analyzed in their study the habit of smoking and resistance to Clopidogrel, where there was no significant difference in the response to this medication in the groups of smoking and non-smoking patients. Although the response to clopidogrel is influenced by the polymorphisms of the Cytochrome $\mathrm{P} 450$ family, the present study found no difference between the CYP2C19*2 polymorphism and the development of restenosis in smoking patients.

Studies comparing individuals with and without polymorphism in the CYP gene, attest that the presence of the polymorphism can cause a lower pharmacokinetic response compared to the individual who does not have polymorphism (Kulmyrzaeva, 2016).

\section{CONCLUSIONS}

We conclude that although the CYP2C19*2 polymorphism alters the response to clopidogrel, its association with smoking did not influence the development of restenosis. Also smoking, regardless of the genetic profile for CYP2C19 allele 2, did not contribute to the main complication of patients with stent, restenosis. A slightly higher frequency of this polymorphism was observed in non-smoking patients, when compared to smokers.

\section{ACKNOWLEDGMENTS}

The authors acknowledge all the personnel directly or indirectly involved in the present research, especially the Pontifical Catholic University of Goiás. There was no funding available for this research.

\section{CONFLICTS OF INTEREST}

The authors declare no conflict of interest. 


\section{REFERENCES}

Almarshad HA and Hassan FM (2016). Alterations in Blood Coagulation and Viscosity Among Young Male Cigarette Smokers of Al-Jouf Region in Saudi Arabia. Clin. Appl. Thromb Hemost. 22: 386-389. doi: $10.1177 / 1076029614561319$.

Anand SS (2017). Smoking: A Dual Pathogen for Arterial and Venous Thrombosis. Circulation. 135: 17-20. doi: 10.1161/CIRCULATIONAHA.116.025024.

Ayesh BM, Al-Astal IR and Yassin MM (2019). The clinical effects of CYP2C19*2 allele frequency on Palestinian patients receiving clopidogrel after percutaneous coronary intervention. Int. J. Clin. Pharm. 41: 96-103. doi:10.1007/s11096-018-00782-3.

Balasubramanian SP, Cox A, Brown NJ and Reed MW (2004). Candidate gene polymorphisms in solid cancers. Eur. J. Surg. Oncol. 30: 593-601. doi: 10.1016/j.ejso.2004.04.001.

Barbosa AM, Dias Neto OS, Freitas e Silva KS, Lima IB, et al. (2020). Lack of association of restenosis with the T786C polymorphism of eNOS in atherosclerotic patients and in silico evidence of interaction between statin and the eNOS protein. Genet. Mol. Res. 19(2): GMR18539. doi: 10.4238/gmr18539.

Caramori PRA, Manfroi WC and Zago AJ (1997). Avaliação clínica dos fatores de risco para a reestenose pósangioplastia coronária. Rev. Ass. Med. Bras. 43: 371-376. doi: 10.1590/S0104-42301997000400017.

Celermajer DS, Sorensen KE, Gooch VM, Spiegelhalter DJ, et al. (1992). Non-invasive detection of endothelial dysfunction in children and adults at risk of atherosclerosis. Lancet. 340: 1111-1115.

Chaudhry AS, Kochhar R and Kohli KK (2009). Importance of CYP2C19 genetic polymorphism in the eradication of Helicobacter pylori in north Indians. Indian J. Med. Res. 130(4): 437-443.

Chistiakov DA, Melnichenko AA, Myasoedova VA, Grechko AV, et al. (2017). Mechanisms of foam cell formation in atherosclerosis. J. Mol. Med. 95: 1153-1165. doi: 10.1007/s00109-017-1575-8.

Cooper RS, Wolf-Maier K, Luke A, Adeyemo A, et al. (2005). An international comparative study of blood pressure in populations of European vs. African descent. BMC Med. 3: 2. doi: 10.1186/1741-7015-3-2.

Craig WY, Palomaki GE and Haddow JE (1989). Cigarette smoking and serum lipid and lipoprotein concentrations: an analysis of published data. BMJ. 298: 784-788.

Friedlander AH and Altman L (2001). Carotid artery atheromas in postmenopausal women. Their prevalence on panoramic radiographs and their relationship to atherogenic risk factors. J. Am. Dent. Assoc. 132: 1130-1136. doi: 10.14219/jada.archive.2001.0340.

Grines CL, Bonow RO, Casey DE Jr, Gardner TJ, et al. (2007). Prevention of premature discontinuation of dual antiplatelet therapy in patients with coronary artery stents: a science advisory from the American Heart Association, American College of Cardiology, Society for Cardiovascular Angiography and Interventions, American College of Surgeons, and American Dental Association, with representation from the American College of Physicians. Circulation. 2007;115(6): 813-818. doi:10.1161/CIRCULATIONAHA.106.180944.

Idrissi H, Hmimech W, Khorb NE, Akoudad H, et al. (2018). A synergic effect between CYP2C19*2, CYP2C19*3 lossof-function and CYP2C19*17 gain-of-function alleles is associated with Clopidogrel resistance among Moroccan Acute Coronary Syndromes patients. BMC Res. Notes. 11(1): 46. doi:10.1186/s13104-018-3132-0.

Jia D, Chen Z, Zhang M, Yang W, et al. (2013). CYP2C19 polymorphisms and antiplatelet effects of clopidogrel in acute ischemic stroke in China. Stroke. 44: 1717-1719. doi: 10.1161/STROKEAHA.113.000823.

Bossard M, Granger CB, Tanguay JF, Steg PG, et al. (2017). Double-Dose Versus Standard-Dose Clopidogrel According to Smoking Status Among Patients With Acute Coronary Syndromes Undergoing Percutaneous Coronary Intervention. J. Am. Heart Assoc. 6(11): e006577. doi:10.1161/JAHA.117.006577.

Kulmyrzaeva N, Tatarunas V, Skipskis V, Smagulova G, et al. (2016). Gene polymorphism of CYP2C19*2, *3 and CYP3A4*1B and early stent thrombosis: case reports and literature review. Per Med. 13(5): 423-428. doi:10.2217/pme-2016-0041.

Lüscher TF (2018). Epidemiology of cardiovascular disease: the new ESC Atlas and beyond. Eur. Heart J. 39: 489-492. doi: 10.1093/eurheartj/ehy070.

Messner B and Bernhard D (2014). Smoking and cardiovascular disease: mechanisms of endothelial dysfunction and early atherogenesis. Arterioscler. Thromb. Vasc. Biol. 34(3): 509-515. doi:10.1161/ATVBAHA.113.300156.

McGill HC and McMahan CA (1998). Determinants of atherosclerosis in the young. Pathobiological Determinants of Atherosclerosis in Youth (PDAY) Research Group. Am. J. Cardiol. 82: 30T-36T. doi: 10.1016/s00029149(98)00720-6.

Neufeld EJ, Mietus-Snyder M, Beiser AS and Baker AL (1997). Passive cigarette smoking and reduced HDL cholesterol levels in children with high-risk lipid profiles. Circulation. 96: 1403-1407.

Nie XY, Li JL, Zhang Y, Xu Y, et al. (2017). Haplotype of platelet receptor P2RY12 gene is associated with residual clopidogrel on-treatment platelet reactivity. J. Zhejiang Univ. Sci B. 18(1): 37-47. doi:10.1631/jzus.B1600333.

Pires MLN, Benedito-Silva AA, Mello MT, Del Giglio S, et al. (2007). Sleep habits and complaints of adults in the city of São Paulo, Brazil, in 1987 and 1995. Braz. J. Med. Biol. Res. 40: 1505-1515. doi: 10.1590/S0100879X2006005000170. 
Sambrook J, Maccallum P and Russel D (2001). Molecular cloning: A laboratory manual, 3nd ed. Cold Springs Harbour Press, NY, ISBN 0-87969-577-3. p. 2344.

Silva SA da, Chrispim PPM, Ju YT and Ribeiro A (2018). Economic Burden of Cardiovascular Diseases in Brazil: Are Telemedicine and Structured Telephone Support the Solution? Arq. Bras. Cardio. 111: 37-38. doi: $10.5935 / \mathrm{abc} .20180136$.

Syvänen AC (2001). Accessing genetic variation: genotyping single nucleotide polymorphisms. Nat. Rev. Genet. 2: 930942. doi: $10.1038 / 35103535$.

Tanindi A, Ekici B, Töre HF (2015). Do pre-procedural laboratory parameters predict drug-eluting stent restenosis? Turk Kardiyol Dern Ars. 43(5): 457-464. doi:10.5543/tkda.2015.48275.

Yi X, Lin J, Wang Y, Wang C, et al. (2016). Association of Cytochrome P450 Genetic Variants with Clopidogrel Resistance and Outcomes in Acute Ischemic Stroke.J. Atheroscler Thromb. 23(10): 1188-1200. doi:10.5551/jat.33290. 